\title{
Bitot spot: early marker for avoidable blindness
}

\author{
Siddharth Madan MBBS MS, Sarita Beri MBBS MD
}

- Cite as: CMAJ 2017 October 10;189:E1264. doi: 10.1503/cmaj.170792

A

$\mathrm{n}$ eight-year-old boy presented to our ophthalmology clinic with a four-month history of dry, itchy eyes and a reluctance to play outdoors during late evening, possibly indicating night blindness. The patient's unaided visual acuity was $6 / 6$ in both eyes. He had triangular, bilaterally symmetric, keratinized patches in the interpalpebral regions over his bulbar conjunctiva, adjacent to the temporal limbus. These features were suggestive of Bitot spots, classified as xerophthalmia stage X1B according to the World Health Organization classification (Figure 1). ${ }^{1}$ His cornea and dilated fundus examination were normal, as were his height and weight for his age. He had dry, brittle nails and skin xerosis involving both lower limbs. We diagnosed vitamin A deficiency and prescribed oral vitamin A 200000 international units to be taken on two consecutive days, and a third dose at 14 days. ${ }^{1}$ We also recommended ocular lubrication. The patient's Bitot spots and night blindness resolved in one month.

Vitamin A deficiency is a major cause of avoidable blindness worldwide in preschool children. Nearly half of all cases are concentrated in Southeast Asia and Africa. ${ }^{2}$ Moderate to severe vitamin A deficiency has been found in $20 \%-60 \%$ of children in refugee camps in Africa, ${ }^{3}$ and is associated with malnutrition, diarrhea and respiratory tract infections. North American physicians treating children from refugee camps in Southeast Asia and Africa may wish to consider the possibility of vitamin A deficiency in children with visual disturbance or dry eyes.

\section{References}

1. Control of vitamin A deficiency and xerophthalmia. Report of a joint WHO/ UNICEF/USAID/Helen Keller International/IVACG meeting. WHO Technical Report Series, No. 672. Geneva: World Health Organization; 1982.

2. Global prevalence of vitamin A deficiency in populations at risk 1995-2005: WHO global database on vitamin A deficiency. Geneva: World Health Organization; 2009:55.

3. Seal AJ, Creeke PI, Mirghani Z, et al. Iron and vitamin A deficiency in long-term African refugees. J Nutr 2005;135:808-13.

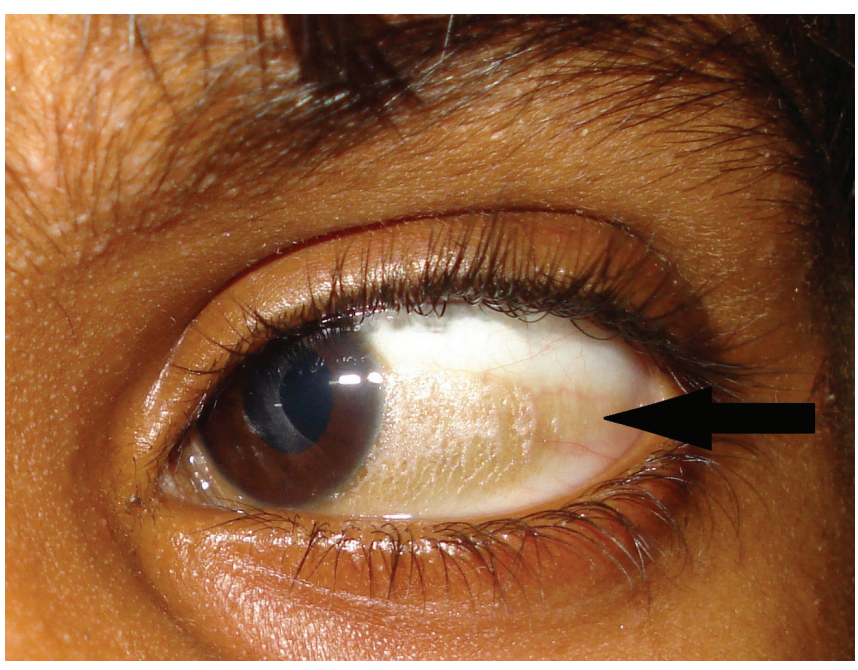

Figure 1: Left eye of an eight-year-old boy, with a large, superficial, triangular, foamy, keratinized patch in the interpalpebral region over the bulbar conjunctiva, adjacent to the temporal limbus (black arrow), suggestive of Bitot spot.

\section{Competing interests: None declared.}

This article has been peer reviewed.

The authors have obtained patient consent.

Affiliation: Department of Ophthalmology, Lady Hardinge Medical College and Associated Smt. Sucheta Kriplani Hospital \& Kalawati Saran Children's Hospital, University of Delhi, New Delhi, India

Correspondence to: Siddharth Madan, drsiddharthmadan@gmail.com

Clinical images are chosen because they are particularly intriguing, classic or dramatic. Submissions of clear, appropriately labelled highresolution images must be accompanied by a figure caption. A brief explanation (300 words maximum) of the educational importance of the images with minimal references is required. The patient's written consent for publication must be obtained before submission. 